\section{Portal Vein Embolization Prior to Extensive Resection for Colorectal Liver Metastases}

\section{TO THE EDITORS:}

We read with great interest the editorial by Prof. Belghiti and colleague published in the April issue of the Annals of Surgical Oncology in response to our paper on long-term survival and disease recurrence following portal vein embolisation prior to major hepatectomy for colorectal metastases. ${ }^{1,2}$

The editorial correctly mentions that a reduced longterm outcome has previously been reported. However the current study is the only publication with an adequate longterm follow-up. In addition the previous reports have not carried out an intention-to-treat analysis, and therefore patients progressing and becoming unresectable following PVE have been excluded from the survival data. ${ }^{3,4}$

Although Prof. Belghiti accepts that tumours may progress after PVE we feel that the evidence is substantial. Published studies have shown a $20-30 \%$ rate of tumour progression after PVE. ${ }^{2,4}$ There is good radiological evidence of increased tumour growth rate ${ }^{5,6}$ and we have recently published molecular evidence for tumour proliferation being stimulated by PVE. ${ }^{6}$ The long-term survival is reduced and there is increased disease recurrence after PVE. $^{2,5}$

We would agree that there is still an important role for PVE in the surgical management of extensive colorectal liver metastases but would caution against use in marginal circumstances. Thorough volumetric assessment should be carried out along with functional studies to determine those who require and are most likely to benefit from PVE. ${ }^{7}$
The mechanism of tumour growth stimulation following PVE requires to be defined so that inhibitory strategies can be employed at the time of embolisation aimed at improving both resectability and long-term survival.

\section{Viniyendra Pamecha, MS, FEBS, and Brian Davidson, MD, FRCS}

Hepato Pancreato Biliary and Liver Transplant Surgery, Royal Free Hospital, University College London, London, UK

e-mail: Viniyendra.Pamecha@ royalfree.nhs.uk

Published Online: 15 July 2009

(C) Society of Surgical Oncology 2009

\section{REFERENCES}

1. Belghiti J, Benhaïm L. Portal vein occlusion prior to extensive resection in colorectal liver metastasis: a necessity rather than an option! Ann Surg Oncol. 2009;16:1098-9. DOI: 10.1245/s10434009-0379-7.

2. Pamecha V, Glantzounis G, Davies N, Fusai G, Sharma D, Davidson B. Long term survival and disease recurrence following portal vein embolisation prior to major hepatectomy for colorectal metastases. Ann Surg Oncol. 2009;16(5):1202-7.

3. Azoulay D, Castaing D, Smail A, et al. Resection of nonresectable liver metastases from colorectal cancer after percutaneous portal vein embolization. Ann Surg. 2000;231:480-6.

4. Mueller L, Hillert C, Möller L, Krupski-Berdien G, Rogiers X, Broering DC. Major hepatectomy for colorectal metastases: is preoperative portal occlusion an oncological risk factor? Ann Surg Oncol. 2008;15:1908-17.

5. Kokudo N, Tada K, Seki M, et al. Proliferative activity of intrahepatic colorectal metastases after preoperative hemihepatic portal vein embolization. Hepatology. 2001;34:267-72.

6. Pamecha V, Levene A, Grillo F, Woodward N, Dhillon A, Davidson BR. Effect of portal vein embolisation on the growth rate of colorectal liver metastases. Br J Cancer. 2009;100(4):617-22.

7. Dinant S, de Graaf W, Verwer BJ, Bennink RJ, van Lienden KP, Gouma DJ, et al. Risk assessment of posthepatectomy liver failure using hepatobiliary scintigraphy and CT volumetry. J Nucl Med. 2007;48:685-92. 